\title{
Multidisciplinary Treatment Options of Tooth Avulsion Considering Dif- ferent Therapy Concepts
}

\author{
Eckehard Kostka ${ }^{1}$, Simon Meissner ${ }^{2}$, Christian H. Finke ${ }^{3}$, Manlio Mandirola ${ }^{3}$ and Saskia Preissner ${ }^{1, *}$ \\ ${ }^{1}$ Department of Operative and Preventive Dentistry, Assmannshauser Straße 4-6, 14197 Berlin, Germany \\ ${ }^{2}$ Department of Oral Medicine, Dental Radiology and Oral Surgery, Assmannshauser Straße 4-6, 14197 Berlin, \\ Germany \\ ${ }^{3}$ Department of Orthodontics, Dentofacial Orthopedics and Pedodontics, Assmannshauser Straße 4-6, 14197 Berlin, \\ Germany
}

\begin{abstract}
Background: Avulsion of permanent front teeth is a rare accident, mostly affecting children between seven and nine years of age. Replanted and splinted, these teeth often develop inflammation, severe resorption or ankylosis affecting alveolar bone development and have to be extracted sooner or later.
\end{abstract}

Objectives: The purpose of this study was to evaluate different therapy concepts to create a structured concept for the treatment of avulsions.

Results: Based on existing therapy concepts, a concept for different initial conditions (dry time, age, growth, tooth, hard and soft tissues) was developed and is presented here.

Conclusion: A great deal of research has been performed during recent years and guidelines for the management of avulsions have been published. With the help of this literature it is possible to identify the best treatment procedure for each tooth.

Clinical Relevance: The prognosis of avulsed teeth can be improved by considering evidence-based therapy concepts. Resorption, ankylosis and tooth loss could be minimized.

Keywords: Tooth avulsion, pulp regeneration, pulp revascularization, tooth loss, tooth replantation, trauma.

\section{INTRODUCTION}

Avulsion is a traumatic displacement of the tooth from its socket. It is an accident, representing $0.5 \%$ to $3 \%$ of traumatic injuries [1] in permanent dentition, mostly affecting children between seven and nine years of age [2]. An adequate management within the first half hour is most important for the prognosis of the tooth. Different medical storage media have been reported to be effective in maintaining [3] the periodontal ligament (PDL) cells in a viable state after avulsion, but milk remains one of the most commonly used and recommended storage media [4]. Its main advantages are high availability, a physiologically compatible $\mathrm{pH}$ and osmolality with the PDL cells. Depending on the injury to the PDL these replanted teeth often develop surrounding inflammation followed by severe resorption ending up in ankylosis [5]. Ankylosis affects alveolar bone development in younger patients [6]. A great resource of help for dentists in

*Address correspondence to this author at the Department of Operative and Preventive Dentistry, Assmannshauser Straße 4-6, 14197 Berlin, Germany; Tel: +4930450562675; Fax: +4930450562932;

E-mail: saskia.preissner@charite.de decision-making and choosing treatment procedures is the Dental Trauma Guide (www.dentaltraumaguide.org) [7]. Within this tool Andreasen also provides a prognosis for each form of trauma based on the analysis of innumerous cases. Meanwhile, there is some evidence-based literature that makes it favorable to modify some of these procedures regarding preparation of the root surface, timing of root canal treatment and systemic medication. A lot of research has been performed during the last years and guidelines for the management of avulsions have been published $[8,9]$. Reviewing this literature it is possible to identify the best treatment procedure for every tooth, but the information is spread over journals and books of different disciplines in dentistry (endodontic, periodontal, orthodontic, pedodontic or surgical publications). For daily practice, it would be helpful to have structured recommendations for treatment protocols under different initial conditions (dry time, age, growth, tooth, hard and soft tissues) relying on existing evidence-based therapy concepts. The first goal of avulsion treatment is to keep the tooth vital or at least functional in place avoiding resorption and ankylosis resulting in normal growth of the alveolar ridge. If this cannot be achieved it is of utmost importance to prevent the alveolar bone from collapsing due to tooth loss. 


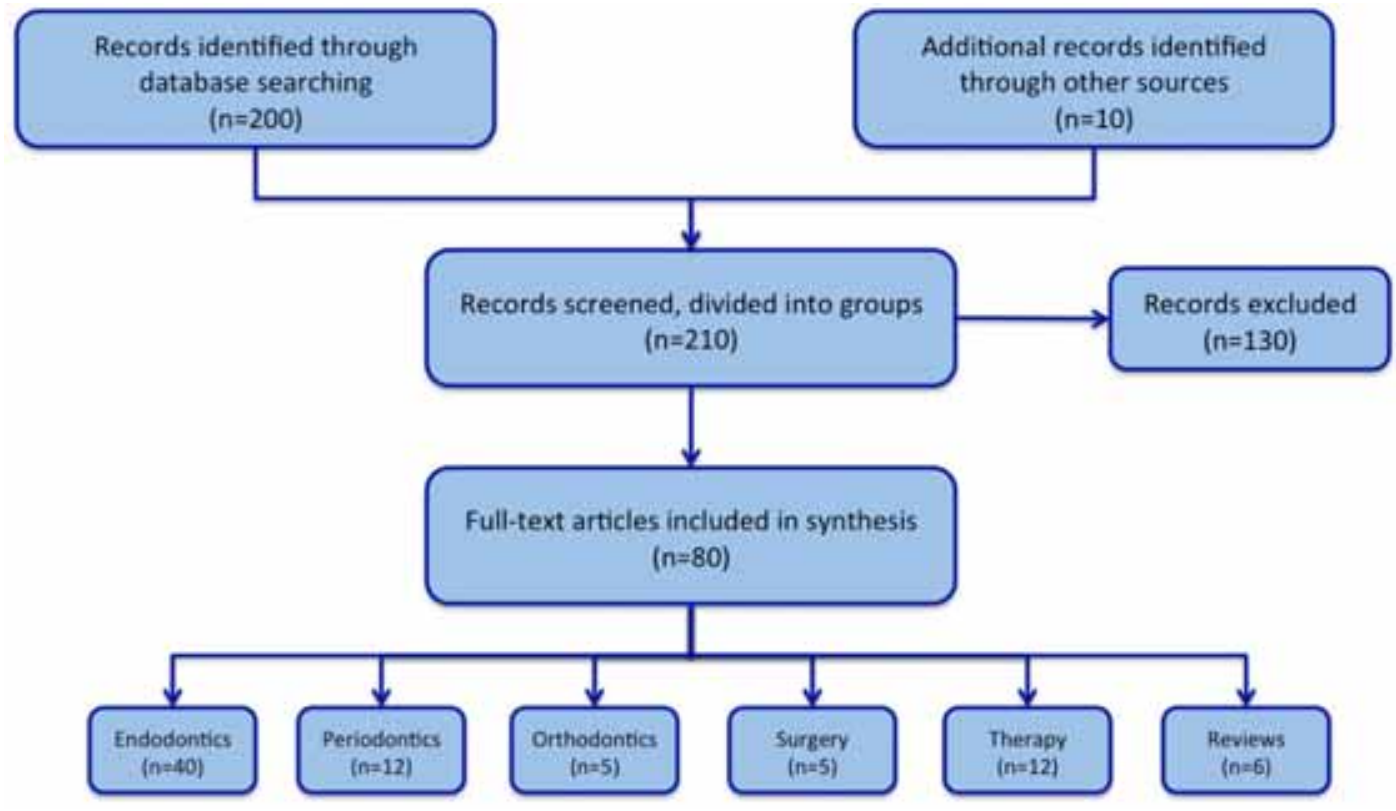

Fig. (1). Flowchart of literature synthesis.

Alveolar bone structure is necessary for the the placement of an implant after completion of alveolar bone development up to the age of 21 or even later.

\section{MATERIALS AND METHODS}

\section{Textmining}

The complete Medline/PubMed data was screened for articles about dental avulsion. Specific keywords were used to retrieve about 200 articles. Ten additional records were identified through other sources (books, articles not indexed in PubMed). The abstracts of those records were screened and 130 were excluded due to evidence-based criteria. About 80 full-text articles were included in the synthesis and divided into groups: Endodontics, Periodontics, Orthodontics, Surgery, Therapy and Reviews (Fig. 1). Specialists in the different disciplines read the articles and met weekly to find a consensus for each problem.

\section{RESULTS AND DISCUSSION}

For easy understanding and fast access a flow chart was developed comprising a synthesis of the evidence-based literature about tooth avulsion. Fig. (2) summarizes the conclusions from the analysis of the literature and offers guidance in determining the optimal treatment concept for any form of tooth avulsion.

\section{Initial treatment}

For the initial treatment it is important to get information about the dry time of the avulsed tooth, because cells of the periodontal ligament (PDL) are irreversibly damaged after 30-60 minutes [8, 10, 11]. Damaged PDL cells lead to fast inflammatory resorption accompanied by ankylosis and a negative influence on alveolar bone growth [6].

\section{Dry time $<30 \mathrm{~min}$}

If the tooth' dry time was under 30 minutes, it is likely that PDL cells have survived and will regenerate $[8,10,11]$. To minimize the risk of inflammatory or replacement resorption an anti-resorption therapy should be performed. This procedure aims onto defending against inflammation caused by bacterial contamination and/or necrotic cells and tissues. Different regimen have been described using antibiotics The anti-resorptive therapy consists of soaking the tooth into a storage media enriched with $800 \mu \mathrm{g}$ doxycyline $(50 \mu \mathrm{m} / \mathrm{ml})$ and $640 \mu \mathrm{g}$ dexamethasone $(40 \mu \mathrm{m} / \mathrm{ml})$ for 20 minutes $[12$, 13]. That time can be used to inspect and clean the alveolus with $0.9 \%$ physiologic saline solution. Afterwards, the tooth is replanted and splinted with a semi-rigid device for instance with a titanium trauma splint (TTS) for 10 days. Additionally the patient is prescribed doxycycline for 5 days. Children under $50 \mathrm{~kg}$ receive $100 \mathrm{mg}$ as an initial dose on the first day and $50 \mathrm{mg}$ on the following days [12]. Intolerances are rare, but if present, amoxicillin is a good alternative. Doxycycline leads to no or little tooth discolorations [14].

After removal of the splint, the mobility of the tooth is tested and a vitality test is performed. The assessment of the vitality of traumatized teeth in younger patients is very challenging, due to the lack of reliability on the reaction of the children. Moreover, ice spray or solid $\mathrm{CO}_{2}$ snow are poorly reproducible during the first weeks after trauma, while electric pulp testing or pulse oximetry are more reliable over longer periods [15-17].

\section{Positive Vitality Test}

A radiograph should be taken with an individualized holder (Fig. 3) which helps to obtain comparable x-rays from the same angle in subsequent follow-ups. After one, three and six months a new x-ray is taken for early recognition of any signs of resorption. If there is no resorption, a recall 


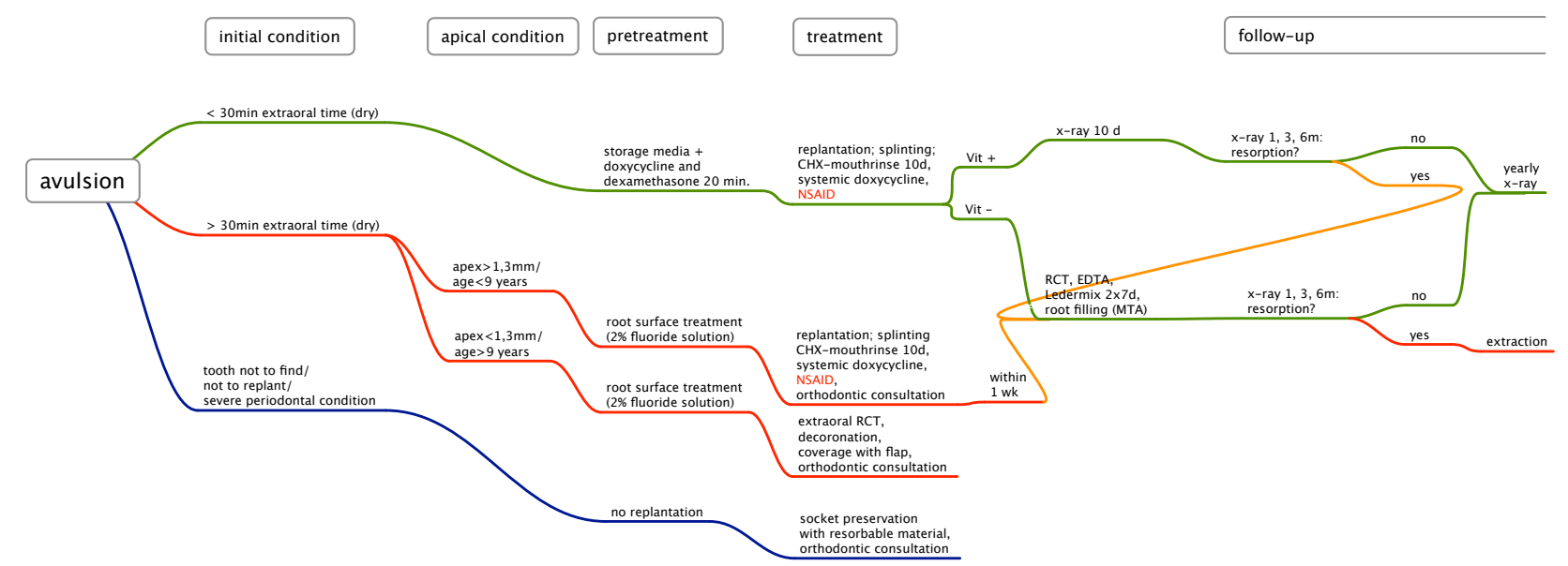

Fig. (2). Flow chart for the avulsion of permanent teeth.

With the help of the Flow chart, clinicians obtain a quick overview of evidence-based treatment options for avulsed teeth.

examination including $\mathrm{x}$-ray should be performed every year. If there are signs of resorption, a root canal treatment (RCT) might stop the inflammatory process [18]. Further treatment follows the procedure for the negative vitality test.

\section{Negative Vitality Test}

If the vitality test is negative after 10 days, there is no chance for revascularisation and RCT has to be performed. To prevent resorption it is important to facilitate diffusion through the dentine by removing the smear layer in the root canal with EDTA irrigation and to put in Ledermix as an intermediate dressing twice for 7 days each time $[19,20]$. The root filling should be performed with a dental microscope to insert the MTA apically [21-23]. The backfill of the remaining root canal can be done with gutta-percha. Radiographs should be performed with an individualized holder. After one, three and six months a new x-ray is taken to recognize signs of resorption.

\section{Dry Time $>30 \mathrm{~min}$}

For extraoral dry times over 30 minutes, it is certain that most PDL cells on the root surface are necrotic and resorptions are to be expected [24]. If possible, an orthodontist should be consulted regarding the expected alveolar bone growth, because there are inter-individual differences in age and growth with the poorest prognosis in children with mature teeth before pubertal spurt $[6,25]$. These results suggest that replanting these teeth should be regarded as a temporary solution to preserve bone to

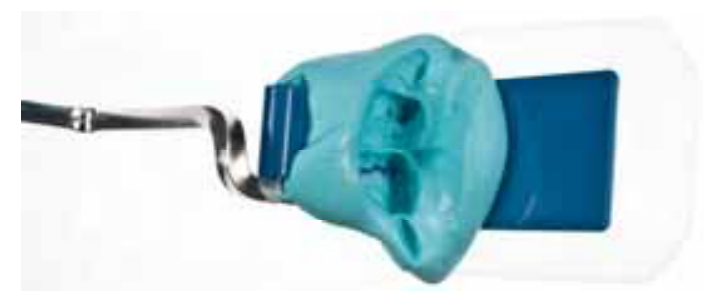

Fig. (3). Individualized holder for comparable x-rays.

The holder can easily be individualized with dental impression material (putty silicone). gain time for a later prosthetic rehabilitation.

\section{Apical Foramen $>1.3 \mathrm{~mm}$}

For younger patients ( $<9$ years) with wide apical openings $(>1.3 \mathrm{~mm})$ an attempt should be made to preserve the tooth. To slow down the resorption process, the root surface is treated with $2 \%$ sodium fluoride for twenty minutes after mechanical cleaning [26]. The procedure according to teeth with dry time $<30$ minutes and negative vitality test follows. The root canal treatment should be performed within one week after replantation with Ledermix as intermediate dressing, as it was found to result in significant less loss in root mass due to resorption $[27,28]$.

\section{Apical Foramen $<1.3 \mathrm{~mm}$}

A tooth with a dry time over 30 minutes and a closed apex has a very poor prognosis, mainly resulting in ankylosis and infra-position due to ongoing skeletal growth. Therefore these teeth cannot be expected to be preserved. The root canal preparation is performed extraorally with Gates-Glidden burs 5-6 (ISO 130-150) and the root surface is treated with $2 \%$ sodium fluoride for five minutes to retard resorption. A decoronation is followed by coverage of the remnant root with a flap $[29,30]$.

\section{Tooth not Found/ not to Replant/ Severe Periodontal Conditions}

If the tooth is lost or not to replant due to complicated fracture or if there are poor periodontal conditions, the focus is laid on socket preservation with collagen and/or a biphasic alloplastic slow resorbable bone substitute and a collagen membrane for alveolar ridge preservation [31]. Implant therapy in children and adolescents may influence maxillary and mandibular skeletal and dental growth [32] and should be postponed until the completion of alveolar bone growth. An orthodontist should be consulted to assess the alveolar bone growth and discuss treatment options [33, 34]. Autotransplantation of premolars is also described as a successful treatment option after tooth loss [35]. 


\section{CONCLUSION}

With the help of the flow chart, clinicians can choose evidence-based treatment procedures quickly and easily. Antiresorptive therapy methods are essential for therapy of the avulsed tooth to avoid/minimize growth retardation of the alveolar ridge. The clinician has a structured directory and pathway by which to validate the chances of success using the considered treatment regimen.

\section{CONFLICT OF INTEREST}

The authors confirm that this article content has no conflict of interest.

\section{ACKNOWLEDGMENTS}

The authors would like to thank Dr. Anna-Katharina Gieren, Charité - Universitätsmedizin Berlin, for discussing about periodontal aspects after tooth avulsion.

\section{REFERENCES}

[1] Andreasen JO, Andreasen FM. Dental trauma: quo vadis. Tandlaegebladet 1989; 93(11): 381-4.

[2] Andreasen JO, Andreasen FM, Andersson L. Textbook and color atlas of traumatic injuries to the teeth. $4^{\text {th }}$ ed: Wiley-Blackwell; 2007.

[3] Udoye CI, Jafarzadeh H, Abbott PV. Transport media for avulsed teeth: a review. Aust Endod J 2012; 38(3): 129-36.

[4] Poi WR, Sonoda CK, Martins CM, et al. Storage media for avulsed teeth: a literature review. Braz Dent J 2013; 24(5): 437-45.

[5] Andreasen FM. Transient root resorption after dental trauma: the clinician's dilemma. J Esthet Restor Dent 2003; 15(2): 80-92.

[6] Kawanami M, Andreasen JO, Borum MK, Schou S, HjortingHansen E, Kato H. Infraposition of ankylosed permanent maxillary incisors after replantation related to age and sex. Endod Dent Traumatol 1999; 15(2): 50-6.

[7] Andreasen JO, Lauridsen E, Gerds TA, Ahrensburg SS. Dental Trauma Guide: a source of evidence-based treatment guidelines for dental trauma. Dent Traumatol. 2012; 28(2):142-7.

[8] Flores MT, Andersson L, Andreasen JO, et al. Guidelines for the management of traumatic dental injuries. II. Avulsion of permanent teeth. Dent Traumatol 2007; 23(3): 130-6.

[9] Hinckfuss SE, Messer LB. An evidence-based assessment of the clinical guidelines for replanted avulsed teeth. Part I: Timing of pulp extirpation. Dent Traumatol 2009; 25(1): 32-42.

[10] Garcia-Godoy F, Murray PE. Recommendations for using regenerative endodontic procedures in permanent immature traumatized teeth. Dent Traumatol 2012; 28(1): 33-41.

[11] Trope M. Avulsion of permanent teeth: theory to practice. Dent Traumatol 2011; 27(4): 281-94.

[12] Pohl Y, Filippi A, Kirschner H. Results after replantation of avulsed permanent teeth. II. Periodontal healing and the role of physiologic storage and antiresorptive-regenerative therapy. Dent Traumatol 2005; 21(2): 93-101.

[13] Petrovic B, Markovic D, Peric T, Blagojevic D. Factors related to treatment and outcomes of avulsed teeth. Dent Traumatol 2010; 26(1): 52-9.

[14] Volovitz B, Shkap R, Amir J, Calderon S, Varsano I, Nussinovitch M. Absence of tooth staining with doxycycline treatment in young children. Clin Ped 2007; 46(2): 121-6.
[15] Gopikrishna V, Tinagupta K, Kandaswamy D. Comparison of electrical, thermal, and pulse oximetry methods for assessing pulp vitality in recently traumatized teeth. J Endod 2007; 33(5): 531-5.

[16] Gutmann JL. Diagnostic pulp testing in dentistry: how far have we come? J Hist Dent 2011; 59(3): 126-8.

[17] Karayilmaz H, Kirzioglu Z. Comparison of the reliability of laser Doppler flowmetry, pulse oximetry and electric pulp tester in assessing the pulp vitality of human teeth. J Oral Rehabil 2011;38(5): 340-7.

[18] Stewart CJ, Elledge RO, Kinirons MJ, Welbury RR. Factors affecting the timing of pulp extirpation in a sample of 66 replanted avulsed teeth in children and adolescents. Dent Traumatol 2008; 24(6): 625-7

[19] Chen H, Teixeira FB, Ritter AL, Levin L, Trope M. The effect of intracanal anti-inflammatory medicaments on external root resorption of replanted dog teeth after extended extra-oral dry time. Dent Traumatol 2008; 24(1): 74-8.

[20] Day PF, Gregg TA, Ashley P, et al. Periodontal healing following avulsion and replantation of teeth: a multi-centre randomized controlled trial to compare two root canal medicaments. Dent Traumatol 2012; 28(1): 55-64.

[21] Nuvvula S, Melkote TH, Mohapatra A, Nirmala S. Management of immature teeth with apical infections using mineral trioxide aggregate. Contemp Clin Dent 2010; 1(1): 51-3.

[22] Panzarini SR, Trevisan CL, Brandini DA, et al. Intracanal dressing and root canal filling materials in tooth replantation: a literature review. Dent Traumatol 2012; 28(1): 42-8.

[23] Sarris S, Tahmassebi JF, Duggal MS, Cross IA. A clinical evaluation of mineral trioxide aggregate for root-end closure of non-vital immature permanent incisors in children-a pilot study. Dent Traumatol 2008; 24(1): 79-85.

[24] Andreasen JO. Effect of extra-alveolar period and storage media upon periodontal and pulpal healing after replantation of mature permanent incisors in monkeys. Int J Oral Surg 1981; 10(1): 43-53.

[25] Ebeleseder KA, Friehs S, Ruda C, Pertl C, Glockner K, Hulla H. A study of replanted permanent teeth in different age groups. Endod Dent Traumatol 1998; 14(6): 274-8.

[26] Barbakow FH, Cleaton-Jones PE, Austin JC, Vieira E. Effects of thyrocalcitonin, acidulated sodium fluoride, and neutral sodium fluoride on the mobility of experimentally replanted teeth. J Endod. 1980; 6(11): 823-8.

[27] Bryson EC, Levin L, Banchs F, Abbott PV, Trope M. Effect of immediate intracanal placement of Ledermix Paste(R) on healing of replanted dog teeth after extended dry times. Dent Traumatol 2002; 18(6): 316-21.

[28] Day P, Duggal M. Interventions for treating traumatised permanent front teeth: avulsed (knocked out) and replanted. Cochrane Database Syst Rev 2010; (1): CD006542.

[29] Cohenca N, Stabholz A. Decoronation - a conservative method to treat ankylosed teeth for preservation of alveolar ridge prior to permanent prosthetic reconstruction: literature review and case presentation. Dent Traumatol 2007; 23(2): 87-94.

[30] Malmgren B. Ridge preservation/decoronation. J Endod 2013; 39(3 Suppl): S67-72.

[31] Kim DM, De Angelis N, Camelo M, Nevins ML, Schupbach P, Nevins M. Ridge preservation with and without primary wound closure: a case series. Int J Periodont Restorat Dent 2013; 33(1): 71-8.

[32] Mankani N, Chowdhary DR, Patil DB, E DN, Madalli DP. Dental implants in children and adolescents: a literature review. J Oral Implant 2012.

[33] Thilander B. Orthodontic space closure versus implant placement in subjects with missing teeth. J Oral Rehabil 2008; 35 Suppl 1: 64-71.

[34] Westwood RM, Duncan JM. Implants in adolescents: a literature review and case reports. Int J Oral Maxillofac Implants 1996; 11(6): $750-5$

[35] Paulsen HU, Andreasen JO. Eruption of premolars subsequent to autotransplantation: a longitudinal radiographic study. Eur J Orthodont 1998; 20(1): 45-55.

This is an open access article licensed under the terms of the Creative Commons Attribution Non-Commercial License (http://creativecommons.org/licenses/by-nc/3.0/) which permits unrestricted, non-commercial use, distribution and reproduction in any medium, provided the work is properly cited. 